\title{
Treatment of Metastatic Bone Pain with Rhenium-188 Hydroxyethylidene Diphosphonate
}

\author{
Shaoliang Chen Kaipin Xu Wenguan Liu Zhifeng Yao Kejing Chen \\ Duanzi Yin Yongxian Wang
}

Institute of Nuclear Medicine, Medical College of Fudan University and Department of Nuclear Medicine, Zhongshan Hospital, Shanghai, China

\begin{abstract}
Key Words
Bone pain control - Skeletal metastases, treatment . ${ }^{188}$ Rhenium-hydroxyethylidene diphosphonate ( ${ }^{188}$ Re-HEDP) - Toxicity - Whole body dynamic scans
\end{abstract}

\begin{abstract}
Objective: This study was designed to evaluate the safety and effectiveness of rhenium-188 hydroxyethylidene diphosphonate ( ${ }^{188} \mathrm{Re}$-HEDP) in patients with skeletal metastases. Methods: Thirty-two patient volunteers with cancer metastasized to bone were included in this study. All patients underwent bone scanning with technetium$99 \mathrm{~m}$ methylene diphosphonate 2 days before the administration of ${ }^{188} \mathrm{Re}-\mathrm{HEDP}$. A dose of $1,110 \mathrm{MBq}$ (30 mCi) of ${ }^{188} \mathrm{Re}-\mathrm{HEDP}$ was injected intravenously and whole body dynamic scans were obtained 1, 2, 3, and 5 days later. Blood and urine samples were collected daily for 5 days and then weekly for 4 weeks. The biokinetic data were obtained and the radiation doses were calculated. The reactions, toxicity and pain relief were corrected. $\boldsymbol{R e}$ sults: No acute reaction or toxicity was evident. Leukopenia was found only in 1 patient with skeletal metastases from prostate cancer. The baseline white blood cell count of $4.3 \times 10^{9} / \mathrm{l}$ (normal range 4.0-10.0) declined to a value of $3.0 \times 10^{9} / \mathrm{l} 1$ week after receiving $1,110 \mathrm{MBq}$ (30 mCi) of ${ }^{188} \mathrm{Re}-H E D P$. The white blood cell count had
\end{abstract}

returned to the baseline category by 4 weeks after injection. No patient was found to be thrombocytopenic. The hemoglobin concentration remained at the baseline level for 6 weeks. The excretion rate of ${ }^{188}$ Re-HEDP in the urine was $62 \%$ of the administered activity during the first 2 days. Twenty-eight of the 32 patients (87.5\%) were able to reduce their analgesic intake. Twenty of the 32 patients $(62.5 \%)$ had a significant improvement in the quality of life while 8 patients $(25 \%)$ had a minor improvement. Conclusion: Most of the patients experienced an improvement in the quality of life without induction of serious bone marrow reduction with this treatment regime. It is therefore concluded that the use of ${ }^{188} \mathrm{Re}-\mathrm{HEDP}$ for treatment of skeletal metastasis appears to be feasible.

Copyright $@$ 2001 S. Karger AG, Basel

\section{Introduction}

At least $75 \%$ of patients with metastatic cancer of the bone develop pain [1, 2]. The pain leads to decreasing mobility, which may result in generalized weakness, mobilization difficulties, risk of thromboembolism, pneumonia, hypercalcemia and atelectasis. Therefore, the control of pain in patients with cancer is an important clinical challenge. The primary goal of therapy is pain relief with

\begin{tabular}{ll}
\hline KARGER & ( ) 2001 S. Karger AG, Basel \\
Fax +416130612 34 & 1011-7571/01/0102-0098\$17.50/0 \\
$\begin{array}{l}\text { E-Mail karger@karger.ch } \\
\text { www.karger.com }\end{array}$ & $\begin{array}{l}\text { Accessible online at: } \\
\text { www.karger.com/journals/mpp }\end{array}$
\end{tabular}

Shaoliang Chen

Professor and Head of Department

Department of Nuclear Medicine, Zhongshan Hospital

Shanghai 200032 (China)

E-Mailslchen@shmu.edu.cn 
an improved quality of life. Three radionuclides are employed for this purpose in clinical practice: phosphorus-32 $\left.{ }^{32} \mathrm{P}\right)$ [3], strontium-89 $\left.{ }^{89} \mathrm{Sr}\right)$ [4] and samarium-153 $\left({ }^{153} \mathrm{Sm}\right)$ [5]. Recently, we successfully labeled hydroxyethylidene diphosphonate (HEDP) with rhenium-188 $\left({ }^{188} \mathrm{Re}\right)$ and analyzed its biodistribution in rats and rabbits. ${ }^{188} \mathrm{Re}$ is an excellent candidate for radiotherapy [6]. It can be easily obtained from a ${ }^{188} \mathrm{~W} / 188 \mathrm{Re}$ generator as a 'no carrier added' radioisotope analogous to the ${ }^{99} \mathrm{Mo} /$ $99 \mathrm{~m} \mathrm{Tc}$ generator. Beta emission with energies of $2.12 \mathrm{MeV}$ (71.6\%) and $1.96 \mathrm{MeV}(25.1 \%)$ are suitable for therapy and the gamma emission of $155 \mathrm{keV}(15 \%)$ allows for imaging and calculating dosimetry. The half-life of $16.9 \mathrm{~h}$ is suitable for treatment and of benefit to minimize toxicity to the whole body [7-12]. This present study was designed to evaluate the safety and effectiveness of ${ }^{188}$ ReHEDP in patients with metastases.

\section{Materials and Methods}

\section{${ }^{188}$ Re Production}

${ }^{188} \mathrm{Re}$ was obtained from an alumina-based ${ }^{188} \mathrm{~W} /{ }^{188} \mathrm{Re}$ generator. The ${ }^{188} \mathrm{~W}$ and the ${ }^{188} \mathrm{~W}$-sodium tungstate solution were produced by irradiation of enriched ${ }^{186} \mathrm{~W}$ provided by the Oak Ridge National Laboratory (Oak Ridge, Tenn., USA). Carrier-free ${ }^{188} \mathrm{Re}$ sodium perrhenate was extracted from the generator eluted with $0.9 \% \mathrm{NaCl}$. The radionuclide purity of ${ }^{188} \mathrm{Re}$ was analyzed by high purity germanium detector and the radiochemical purity of $\mathrm{Na}^{188} \mathrm{ReO}_{4}$ by paper chromatography developed with $0.9 \% \mathrm{NaCl}$ as the solvent.

\section{Preparation of ${ }^{188}$ Re-HEDP}

The ${ }^{188} \mathrm{Re}$-HEDP was prepared from a sterile, lyophilized kit provided by the Institute of Nuclear Research. Each vial of the kit contains $20 \mathrm{mg}$ of HEDP, $10 \mathrm{mg}$ of vitamin $\mathrm{C}$ and $10 \mathrm{mg}$ of $\mathrm{SnCl}_{2} \cdot 2 \mathrm{H}_{2} \mathrm{O}$. Four milliliters of the ${ }^{188} \mathrm{Re}$-perrhenate solution was added to the kit and heated in a boiling water bath for $10 \mathrm{~min}$, which was then passed through a $0.22-\mu \mathrm{m}$ filter into a nitrogen-purged vial. The final product was assayed by a high purity germanium detector and paper chromatographic analyses using acetone as solvents. Sterility and pyrogen tests were performed.

\section{Patients}

Thirty-two patients, 23 men and 9 women, with progressive, painful and extensive skeletal metastases from cancer volunteered for the therapeutic protocol. The mean age was $60.4 \pm 8.2$ years (range 30-76 years). To participate, the white blood cell count had to be at least $4.0 \times 10^{9} / 1$ with a total platelet count of at least $100 \times$ $10^{9} / 1$.

\section{Therapeutic Protocol}

All patients underwent bone scanning with technetium- $99 \mathrm{~m}$ methylene diphosphonate ( $99 \mathrm{mTc}-\mathrm{MDP}) 2$ days before the administration of ${ }^{188} \mathrm{Re}-\mathrm{HEDP}$. A dose of $1,110 \mathrm{MBq}(30 \mathrm{mCi})$ of ${ }^{188} \mathrm{Re}-$ HEDP was injected intravenously and whole body scans were obtained $1,2,3$, and 5 days later. The ratio of tumor to normal bone of the contralateral side (T/NT ratio) was calculated. The biokinetic data were obtained and the radiation doses were calculated. The reactions, toxicity and the extent of the pain relief were corrected. For investigation of the toxicity of the radiopharmaceutical, hemoglobin concentration, leukocyte count, platelet count and renal function (plasma creatinine) were studied. Blood and urine samples were collected daily for 5 days, then weekly for 4 weeks and the volume was recorded. The radioactivity in $1 \mathrm{ml}$ of each urine sample was counted in a counter.

The method for pain assessment previously discussed in detail by Turk and Okifuji [13] and other authors [14, 15] was used. Briefly, a box intensity scale was used to assess the patient's pain. A diary containing validated self-reports of rating scales of pain intensity was maintained for more than 30 days.

\section{Results and Discussion}

The average radionuclidic and radiochemical purities were 99 and $98 \%$, respectively. No acute reaction or toxicity was evident.

Leukocytes. Leukopenia was found only in 1 patient with skeletal metastasis from prostate cancer. The baseline white blood cell count of $4.33 \times 10^{9} / 1$ (normal range $\left.4.0-10.0 \times 10^{9} / 1\right)$ declined to a value of $3.0 \times 10^{9} / 1$ 1 week after receiving $1,110 \mathrm{MBq}(30 \mathrm{mCi})$ of ${ }^{188} \mathrm{Re}-$ HEDP. The white blood cell count had returned to the baseline level 4 weeks after injection.

Platelets. All of the patients' platelet counts remained at the baseline value. No patient was found to be thrombocytopenic.

Hematopoietic Toxicity. In all of the 32 patients, the hemoglobin concentration remained at the baseline level during the 6 weeks. Based on these results, hematopoietic toxicity of ${ }^{188} \mathrm{Re}-\mathrm{HEDP}$ after injection of $1,110 \mathrm{MBq}$ (30 $\mathrm{mCi})$ seems to be limited.

Renal Function. Only 1 patient experienced mild renal toxicity with serum creatinine concentrations greater than $140 \mu \mathrm{mol} / 1(1.6 \mathrm{mg} / \mathrm{dl})$ at 1 week post injection of ${ }^{188} \mathrm{Re}-$ HEDP. The serum creatinine returned to normal baseline level at 3 weeks after injection. Results of urinalyses in the other subjects were variable, but none developed elevated serum creatinine levels.

\section{Biodistribution}

Urine. The excretion rate of ${ }^{188} \mathrm{Re}-\mathrm{HEDP}$ in the urine was $62 \%$ of the administered activity within the first 2 days (fig. 1). Figure 2 is the bone scan of ${ }^{188}$ Re-HEDP taken about $24 \mathrm{~h}$ after injection in a patient with skeletal metastasis from prostate cancer. For comparison, the whole body bone scan of $99 \mathrm{mTc}-\mathrm{MDP}$ in the same patient is also shown. These images, obtained 1, 2, 3, and 5 days 


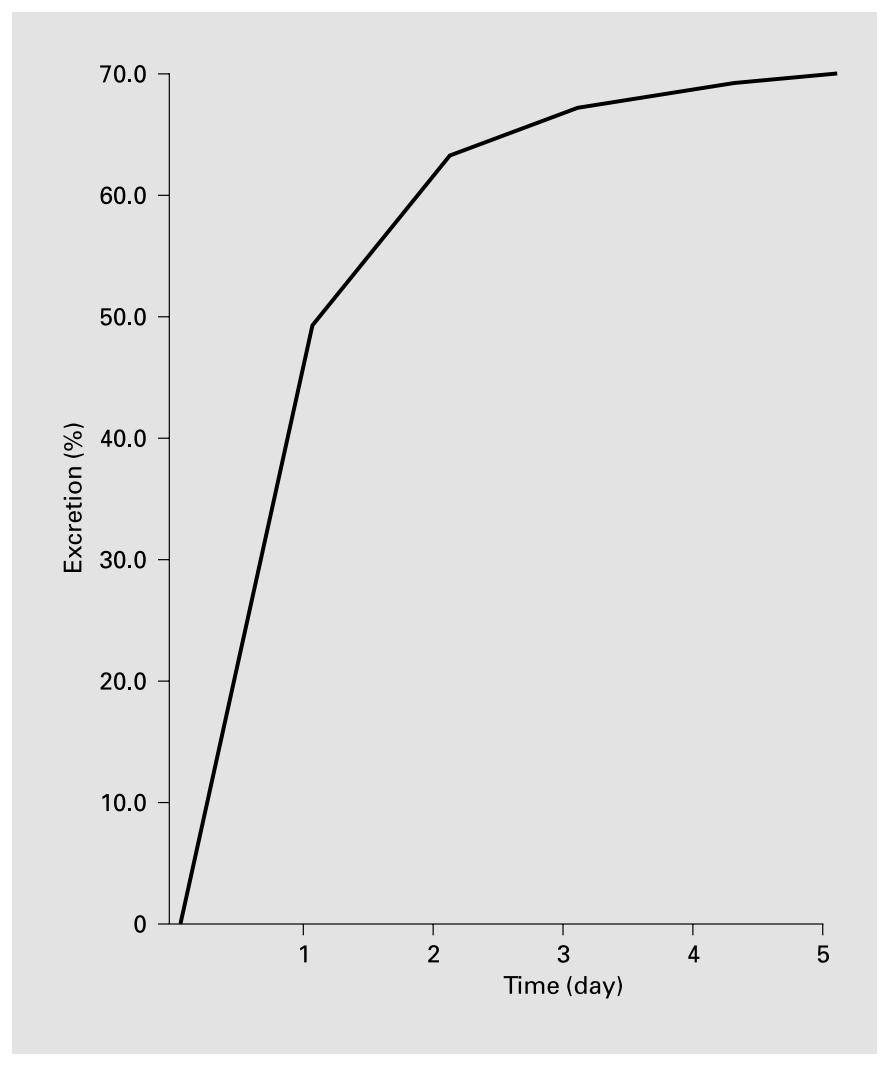

Fig. 1. The urine excretion of ${ }^{188}$ Re-HEDP.

after injection, revealed low soft-tissue activity and high bone accumulation of ${ }^{188} \mathrm{Re}-\mathrm{HEDP}$. The accumulation in lesions that had metastasized was higher than that in normal bone.

\section{Pain Relief}

Three of the 32 patients (9.4\%) experienced a transient increase in pain shortly after the injection of ${ }^{188} \mathrm{Re}-$ HEDP. No other acute reactions occurred. Twenty of the 32 patients $(62.5 \%)$ experienced marked pain relief. The pain relief continued during the final 5-week follow-up visit. Eight of the 32 patients $(25 \%)$ who responded also had a reduction in pain medication of at least $50 \%$. The other 4 patients $(12.5 \%)$ had no response to these treatments. They did not obtain pain relief. In this group, 28 of 32 patients were able to reduce their analgesic intake. Twenty of 23 patients had a significant improvement in the quality of life whereas 8 patients had a minor improvement. Therefore, a positive response, as indicated by at least a $50 \%$ reduction in pain and/or analgesic usage, was seen in 28 out of $32(87.5 \%)$ patients.

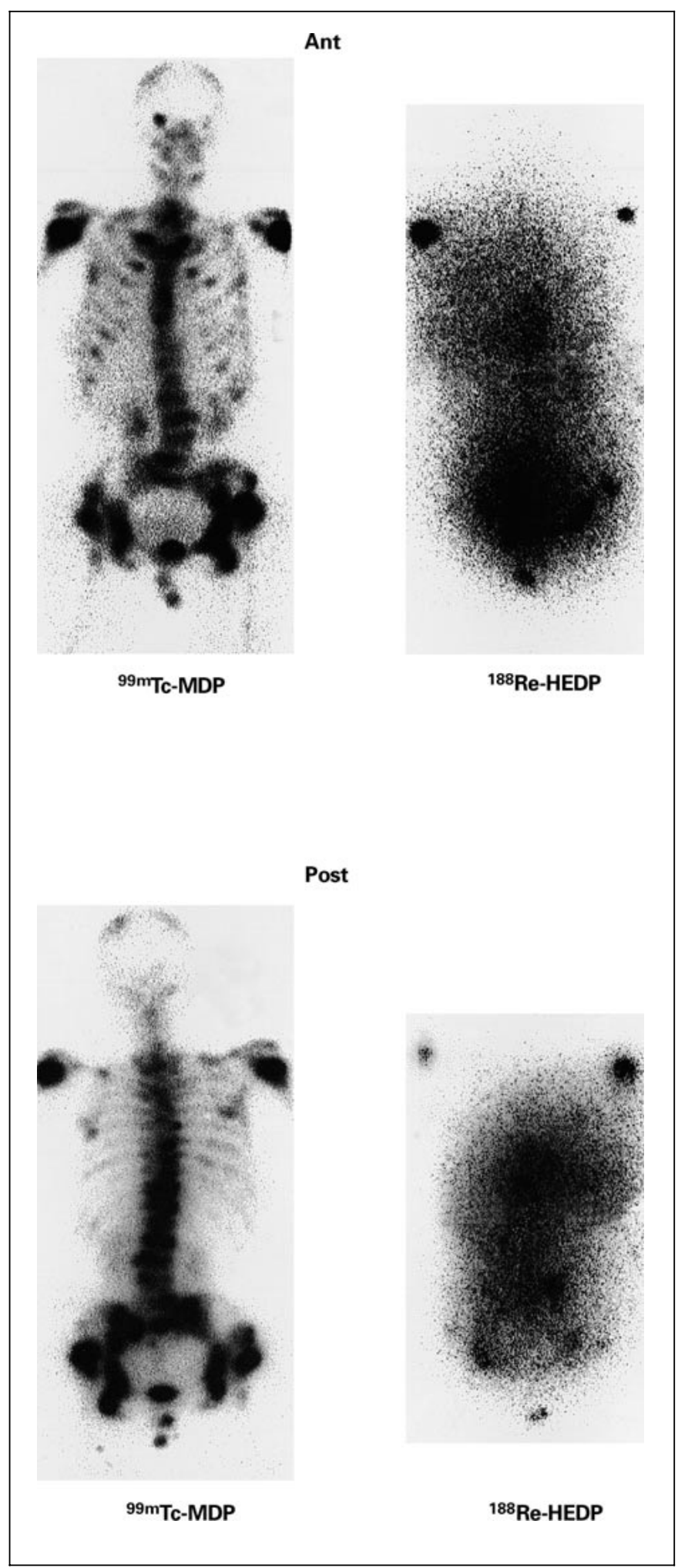

Fig. 2. The bone scan of ${ }^{188} \mathrm{Re}-\mathrm{HEDP}$ about $24 \mathrm{~h}$ after injection in a patient with skeletal metastases from prostate cancer and for comparison a bone scan using ${ }^{99 \mathrm{~m}} \mathrm{Tc}-\mathrm{MDP}$. 
The findings of this study may broaden the use of radiopharmaceuticals for treatment of metastatic bone pain. Compared to the other agents, such as ${ }^{153} \mathrm{Sm}$-ethylenediaminetetramethylene phosphoric acid, ${ }^{188}$ Re-HEDP has a number of advantages: ${ }^{188} \mathrm{Re}$ can be produced from a radionuclide generator and hence be readily available and offer the opportunity of being widely used; ${ }^{188} \mathrm{Re}$ has a reasonably short half-life $(17 \mathrm{~h})$ suitable for treatment and causes less radiotoxicity than ${ }^{153} \mathrm{Sm}\left(\mathrm{t}_{1 / 2} 1.95\right.$ days), ${ }^{186} \operatorname{Re}\left(\mathrm{t}_{1 / 2} 3.7\right.$ days) and ${ }^{89} \mathrm{Sr}\left(\mathrm{t}_{1 / 2} 53\right.$ days). The maximum penetration range of ${ }^{188} \mathrm{Re}$ is longer than that of ${ }^{89} \mathrm{Sr}$, ${ }^{153} \mathrm{Sm}$ or ${ }^{186} \mathrm{Re} .{ }^{188} \mathrm{Re}$ has gamma ray $(\mathrm{E} \gamma 155 \mathrm{keV})$ suit- able for imaging and therefore does not require the administration of another radiopharmaceutical for radionuclide imaging to monitor the efficacy of treatment.

\section{Conclusion}

Most of the patients experienced an improvement in the quality of life without induction of serious bone marrow reduction with this treatment regime. Therefore, it is concluded that the use of ${ }^{188} \mathrm{Re}-\mathrm{HEDP}$ for treatment of skeletal metastasis appears to be feasible.

\section{References}

1 DeNardo GL: Bone pain palliation. Cancer Biother Radiopharm 1998;13:407-412.

2 Loeser JD, Melzack R: Pain: An overview. Lancet 1999;353:1607-1609.

3 Silberstein EB, Elgazaar AH, Kapilivsky A: Phosphorus-32 radiopharmaceuticals for the treatment of painful osseous metastases. Semin Nucl Med 1992;22:17-27.

4 Robinson RG, Preston DF, Spicer JA, Baxter KG: Radionuclide therapy of intractable bone pain: Emphasis on strontium-89. Semin Nucl Med 1992;22:28-32.

5 McEwan AJB: Palliative therapy with bone seeking radiopharmaceuticals. Cancer Biother Radiopharm 1998;13:413-426.

6 Knapp FF Jr, Beets AL, Guhlke S, Zamora PO, Bender H, Palmedo H, Biersack HJ: Availability of rhenium-188 from the alumina-based tungsten-188/rhenium-188 generator for preparation of rhenium-188-labeled pharmaceuticals for cancer treatment. Anticancer Res 1997 . 17:1783-1795.
7 Wunderlich G, Pinkert J, Franke WG: Studies on the processing and in vivo stability of Re188-labelled microspheres; in Oehr $\mathrm{P}$ (ed): Technetium, Rhenium and Other Metals in Chemistry and Nuclear Medicine. New York, SGE Editoriali, 1999, pp 709-712.

8 Wang SJ, Lin WY, Chen MN, Hsieh BT, Shen LH, Tsai ZT, Ting G, Knapp FF Jr: Biodistribution of rhenium-188 Lipiodol infused via the hepatic artery of rats with hepatic tumours. Eur J Nucl Med 1996;23:13-17.

9 Wang SJ, Lin WY, Chen MN, Hsieh BT, Shen LH, Tsai ZT, Ting G, Knapp FF Jr: Radiolabelling of lipidol with generator-produced ${ }^{188} \mathrm{Re}$ for hepatic tumour therapy. Appl Radiat Isot 1996;47:267-271.

10 Jufeng Y, Duanzhi Y, Xiaofeng M, Zili G, Jiong Z, Yongxian W, Knapp FF Jr: [188 Re] rhenium sulfide suspension: A potential radiopharmaceutical for tumor treatment following intra-tumor injection. Nucl Med Biol 1999;26: 573-579.

11 Jufeng Y, Duanzhi Y, Xiaofeng M, Zili G, Jiong Z, Yongxian W, Knapp FF Jr: Preparation of $[188 \mathrm{Re}]$ rhenium sulfide suspension and its biodistribution following intra-tumor injection in mice. $\mathrm{J}$ Labelled Compounds Radiopharm 1999;42:233-243.
12 Macon HR, Schroder LE, Washburn LC, Thomas SR, Samaratunga RC, Biniakiewicz BL, Moulton JS, Cummings D, Ehrhardt GJ, Morris V: Rhenium-188(Sn) HEDP for treatment of osseous metastases. J Nucl Med 1998;39: 659-663.

13 Turk DC, Okifuji A: Assessment of patients' reporting of pain: An integrated perspective. Lancet 1999;353:1784-1788.

14 Han SH, Zonneberg BA, de Klerk JMH, Quirijnen JM, van het Schip $\mathrm{AD}$, van Dijk A, Blijham GH, van Rijk PP: ${ }^{186}$ Re-etidronate in breast cancer patients with metastatic bone pain. J Nucl Med 1999;40:639-642.

15 Palmedo H, Guhlke S, Bender H, Sartor J, Schoeneich G, Risse J, Grünwald F, Knapp FF Jr, Biersack HJ: Dose escalation study with rhenium-188 hydroxyethylidene diphosphonate in prostate cancer patients with osseous metastases. Eur J Nucl Med 2000;27:123-130. 